\section{Scientists' rituals are ripe for investigation}

I suspect that many aspects of the ritual behaviour being investigated by anthropologist Harvey Whitehouse and his colleagues (Nature 493, 470-472; 2013) could well apply to academia, and to the scientific community in particular.

Science generally operates in what Whitehouse calls the 'doctrinal mode', but the 'imagistic mode' might also be relevant. Examples of the doctrinal mode include the ritual of the weekly lab meeting, the bonding induced by social outings, the ritualized nature of scientific conferences and the stereotypical behaviour of different lab members as they go about their research.

For the imagistic mode, what about the agony or ecstasy of having your paper rejected or accepted by Nature? Or the terrified first-year $\mathrm{PhD}$ student who has his or her results lambasted at a lab meeting or, worse, at a conference? It is not unknown for people to crumple under the onslaught of such a "traumatic ritual".

Studying the scientific community would be less dangerous than spending seven months in the middle of a civil war, and might encourage scientists to consider their own ritual behaviours.

Denis R. Alexander The Faraday Institute for Science and Religion, Cambridge, UK.

dra24@hermes.cam.ac.uk

\section{Inertia is speeding fish-stock declines}
A bluefin tuna weighing
222 kilograms sold for
$¥ 155$ million (US\$1.7 million) in
Tokyo last month. This is an all- time record price for a single fish, driven skywards by increasing demand and dwindling supply.
Populations of bluefin tuna (Thunnus spp.) are a fraction international support is needed to sustain these encouraging results.
Iranian scientists have developed a useful model for treating drug addiction and preventing transmission of HIV (C. S. Todd et al. Curr. HIV/ AIDS Rep. 4, 151-157; 2007)

of what they were 50 years ago

(see, for example, go.nature. com/5advqj), in large part because of the increasing value of the high-end sushi and sashimi market. Individuals are caught long before they reach full size (around $650 \mathrm{~kg}$ ).

Conservation is being delayed as economic and political interests override biological concerns. The Convention on International Trade in Endangered Species of Wild Flora and Fauna helps to protect imperilled species, but has evaluated barely $3 \%$ of described species since it came into force in 1975. Similarly, the International Union for Conservation of Nature (IUCN) lists fewer than 100 fish species out of a total of 25,000 in any of the categories of its Red List of threatened species.

Even when complete information is available for heavily affected marine species (giant flatfish and billfish, for example), the IUCN's worldwide voting procedures impose delays on ranking in the list.

Kelly Swing Tiputini Biodiversity Station, University San Francisco de Quito, Quito, Ecuador.

kswing@usfq.edu.ec

\section{Iran needs global support to fight HIV}

HIV infection rates have halved over the past decade in much of the developing world. In the Middle East, meanwhile, they have increased by more than $35 \%$. There are 96,000 people living with HIV/AIDS in Iran alone, with new infections increasing most rapidly among women. Efforts to control the virus are starting to pay off, but that has brought the spread of HIV among injecting drug users under control. But Iran will need to adapt its response as the epidemic shifts to new populations.

HIV researchers, clinicians and policy-makers from the United States, Europe and the Middle East met in Tehran last year to identify priority targets. These include preventing mother-tochild transmission, expanding treatment programmes and reducing infection risk in key populations (see iranhivandaidscongress.org).

International collaborations will help Iran to meet these public-health challenges.

Kayvon Modjarrad National Institute of Allergy and Infectious Diseases, Bethesda, Maryland, USA.

kayvon.modjarrad@nih.gov Minoo Mohraz Tehran University of Medical Sciences, Tehran, Iran.

Navid Madani Dana-Farber Cancer Institute, Boston, Massachusetts, USA.

\section{Educate physicians about investor types}

As a venture capitalist at a US investment fund that supports young pharmaceutical companies, I believe that the misuse of clinical experts by a few hedge-fund investors should not prevent interaction with physicians (Nature 493, 271-272, 280-281;2013). Increasing regulation would risk stigmatizing physician participation in such expert networks, stifling information flow for investors and ultimately impeding drug discovery.

Academic and hospital conflict-of-interest policies that target or ban engagement with investment firms would need to differentiate between investor types. Hedge-fund investors operate in public markets and aim for a quick profit by betting on variables such as clinical-trial data, sales announcements or regulatory approval. Venture capitalists, by contrast, operate in private markets and aim for company growth over several years before selling to a large multinational or to investors through a public stock-market offering.

Unlike hedge-fund investors, venture capitalists holding public securities as insiders cannot profit by selling stock before the release of data. Furthermore, their interests are not threatened by confidential information leaks because of the longer-term nature of their investments.

It would be preferable for investors to identify conflicts of interest with respect to specific drugs before interviewing physicians, and to educate these experts formally on the potential pitfalls of engaging with investors.

Justin Chakma Thomas, McNerney and Partners, La Jolla, California, USA.

jchakma@tm-partners.com

\section{Fungus did not cause potato famine}

The agent responsible for the blight that caused the nineteenth-century Irish potato famine, Phytophthora infestans, should not be "grouped with fungi" (Nature 493, 154-156; 2013).

It was Anton de Bary, the father of mycology, who coined the genus name Phytophthora ('plant-destroyer') and classed the pathogen as a fungus. But modern molecular sequencing indicates that his interpretation was incorrect (M. D. M. Jones et al. Nature 474, 200-203; 2011).

The organism is actually an oomycete, a pseudo-fungus that evolved from killer ancestors in the ancient oceans and not from wood-degrading fungi.

U. Kutschera Institute of Biology, University of Kassel, Kassel,

Germany.

kut@uni-kassel.de 